\title{
The Impact of the Perceived Self-Efficacy on the Academic Adjustment among Qassim University Undergraduates
}

\author{
Safaa M. A. Yadak \\ Qassim University, Al-Rass, Saudi Arabia \\ Email: wthxmy@gmail.com
}

How to cite this paper: Yadak, S.M.A. (2017) The Impact of the Perceived SelfEfficacy on the Academic Adjustment among Qassim University Undergraduates. Open Journal of Social Sciences, 5, 157-174. http://dx.doi.org/10.4236/jss.2017.51012

Received: December 25, 2016

Accepted: January 13, 2017

Published: January 16, 2017

Copyright $\odot 2017$ by author and Scientific Research Publishing Inc. This work is licensed under the Creative Commons Attribution International License (CC BY 4.0).

http://creativecommons.org/licenses/by/4.0/

\section{(c) (i) Open Access}

\begin{abstract}
The main purpose of the study was to explore the impact of the perceived self-efficacy on the academic adjustment among a sample of Qassim University female undergraduates. Two tests were utilized; the perceived self-efficacy and the academic adjustment, the validity and reliability of the tests were insured. A sample of 150 undergraduate from Qassim University enrolled in the first semester of the academic year 2016/2017 from the faculty of Arts and sciences/Ar-Rass, the participants were selected by the simple random technique. The participants level of the perceived self-efficacy was low, the means scores range between $1.05-1.61$, the social dimension score was the highest $(M=1.61)$, and the emotional dimension score was the lowest $(M=1.05)$, the overall means of the test score was 1.38; the academic adjustment score was also low the means range between $1.05-1.28$, the academic dimension means score was high $(M=1.21)$, and the teacher-learner relationship score was low $(\mathrm{M}=1.05)$, the overall means of the test was 1.21 . The statistical correlation between the emotional dimension and the academic adjustment dimensions was not significant. But a significant statistical correlation was found between the dimension of determination and perseverance, the cognitive dimension and the overall perceived self-efficacy and the academic dimension.
\end{abstract}

\section{Keywords}

Perceived Self-Efficacy, Gender, Academic Adjustment, Qassim University, Undergraduates

\section{Introduction}

The most apparent aspect of the differences between the student's in classes is attributed to their ability levels to follow explanation of the lesson, interest to 
acquire educational experiences and focus on information sequence. Some students find it easy to focus and acquire the information provided, others lack the ability to do so, and some of them are easily distracted and this limits their continuous acceptance of the provided educational experience.

Self-efficacy is an important dimension in the learners' personality because of its impact on his behavior and actions. Self-efficacy plays a vital role in directing and determining the learner's behavior, he acts based on his thoughts about himself, this mean an interchangeable process between the way and how he perceives himself; this process is referred to as the academic adjustment [1]. Learners Perceiving their academic self-efficacy proved to have high abilities in; academic adjustment, challenge, performing the extra effort tasks, adjustment to the university activities, agreement with faculty members, less vulnerability to others disorders and self-organized [2].

The perceived self-efficacy is a relatively modern variable; it was derived from Bandura (cited in [3], p. 83) concept of the Social Learning Theory, the concept refers to the belief or the perception of the individuals' level or effectiveness about his own ability to perform tasks, and the mental, cognitive and emotional elements involved and used to address situations, tasks or problems to achieve something in light of the environmental limitations.

In other words the perceived self-efficacy represents the learners ability to plan and practice the effective behavior in order to achieve the desired result in a certain situation, to control the events and situations that affect his life, to issue the right self-expectations about his own ability to perform certain tasks and activities and to predict the extent of the efforts and perseverance needed for the work [4]. Thus, perceived self-efficacy represents the total expectations which the learner forms about himself and believes it will bring him success; this belief increases his self-respect and the will to develop it.

Efficacy feelings are determined by some limitations that interact and work as basic processes that activate the perceived self-efficacy feelings. These determinants as Bandura (cited in [1], p 41) are categorized into; the cognitive processes, the motivational processes, the affective processes and the selection processes, he referred to four main sources through which the learner achieves high levels of efficacy; the successful experiences, having a model characterized by high levels of perceived self-efficacy which enhances the learner belief of his abilities and efficacies in addition to depending on the similarity between it and the form that the learner sees, the social persuasion that increases the learners' verbal confidence and efficacy in performing the task increases in its turn his self-efficacy feelings, the last is modifying the self-beliefs toward the efficacy that is a result of the others reactions and pressures, the adjustment of negative feelings, tendencies and misunderstanding. After all the important matter is how the others perceive and explain the perceived efficacy.

Efficacy feeling work as a cognitive mechanism that contribute in changing the behavior, and accordingly the degree of effectiveness that determine the expected behavior of the learner to confront the problem, as well as the level of the 
effort required to overcome the problem, efficacy feelings does not determine the behavior pattern only but also the most effective one [4], he believes that the efficacy emotions hold a main role to determine and explain human tendencies. The perceived self-efficacy affects the thinking styles, behaviors and emotional excitement. Higher levels of efficacy increase achievement motivation and decrease the emotional excitement, for that the efficacy works as an important category of motivation and behavior determinant on the basis of its correlation with the cognitive, behavioral and environmental processes, which Bandura (cited in [1], p. 41) referred to as the enviable exchange in his theory that leads to academic adjustment.

For the purpose of the current study the author constructed a test of the perceived self-efficacy to measure the four dimensions included; the emotional, social, the determination and perseverance and the cognitive dimensions.

Academic adjustment has different definitions by educational scholars, but there is some similarity between the definitions provided; following is a review of few definitions and their significance.

Arkoff (cited in [5], p. 707) defined adjustment scientifically as "the individuals' interaction with his environment". Young (cited in [5], p. 707) defined it as the flexibility that allows the individual to adjust and change his tendencies and behavior in order to confront difficult situations. Eysenck and Arnold [6] define adjustment as a state in which the needs and of the individual on the one hand and the requirements of the environment are totally satisfied, and there is harmony between the individual, social environment and the goal.

Ahmed [7] defines it as a balance moment that results from the individual conflict with his environment, potentials and the available opportunities. The author of the current study adopted the definition of [8], he provided a definition of two parts; the individual balance and agreement with himself, that is his ability to confront and resolve internal conflicts and frustrations, the extent of his freedom of stress and anxiety, his success in adjusting his motivations and desires, then his agreement with his physical and social environment including relationships with others and different issues and events.

The academic adjustment refers to the final output of the dynamic constructive relationship between the learner and his university environment, which enhances the scientific and personal development of the learner. The good indicators of the relationship are represented by educational hardworking, satisfaction, acceptance and agreement with the university standards and completion of tasks in time, manner and organization [9].

For the purpose of the current study, the author constructed a test of the academic adjustment to measure the dimensions of the academic, the tendency toward the university and the teacher-learner relationship dimensions.

\section{Literature Review}

As far as the author knows, studies tackling the impact of the perceived selfefficacy and its correlation with the academic adjustment are very few, especially 
considering the two variables together, but some studies tackled each variable on its own. So the literature review of the current study is divided into two sections;

\subsection{The Perceived Self-Efficacy}

Hanover [10] studied the role of gender in developing the perceived self-efficacy, one hundred and eighty seven undergraduates participated in the study, and they completed the perceived self-efficacy test. The results indicated a basic role of the gender in developing perceived self-efficacy, and the differences in the methods by which males and females change over time may be attributed to gender standardized stereotype and the differences in own properties.

Akanbi and Ogundokun [11] explored the extent of the effectiveness of a strategy based on perceived self-efficacy in reducing test anxiety among students. Nursing students (No. 250) participated in the study. It was found that the students who received the strategy based on perceived self-efficacy were significantly improved in academic performance compared with the control group of the study, an interaction was found between test anxiety and the perceived selfefficacy in the level of the academic performance.

Nasasrah [12] explored perceived self-efficacy correlation with test anxiety in light of demographical variables among high school students, and he identified the differences in the gender and educational level. The participants were (678) male and female students. The author utilized the perceived self-efficacy and anxiety tests. A negative significant correlation between the perceived self-efficacy and test anxiety was found. No significant statistical differences between averages are found on self-efficacy attributed to the gender and the educational level.

Alwan [13] attempted to find the perceived self-efficacy level among the university students. The sample was selected in a random technique and included equal numbers of male and female students (No. 300); they were enrolled in literary and scientific majors. The author constructed a self-perceived self-efficacy test by the literature of other scholars who tackled the same topic. Student's level of the perceived self-efficacy was statistically significant attributed to different genders, and statistically significant differences were also found in favor of scientific majors undergraduates.

\subsection{The Academic Adjustment}

Az-Zahrani [14] studied the correlation between the sociopsychological development, academic adjustment and academic achievement. Secondary school male and female students at Taif/Saudi Arabia participated in the study. A statistical significant correlation was found between sociopsychological development and the academic adjustment.

Mohanraj and Lath [15] explored the correlation between the family environment, family adjustment and academic achievement among a sample of (109) adolescents, their age range from $14-16$ years. Functional correlations were found between certain factors in the family environment and both of the family adjustment and the academic achievement. Most of the participants recognized 
that their families are organized coherent and directed toward achievement.

Abdullah, Elias, Mahyuddin and Uli [16] tested the academic adjustment of the first year students in a public Malaysian university studying in 6 different majors, the participants (No. 250) completed the Barker Academic Adjustment test. By analyzing the results the academic adjustment proved to be important for the students to success in their life in the university, the academic adjustment level was moderate and males' academic adjustment means scores outperformed the females.

Rashid [5] explored the correlation between the social, personal and academic adjustment among high school students in the middle governorate in Bahrain. The author compared between males and females individual, social and academic adjustment. The participants (No. 203) were 90 male and 113 female students. A correlation was found between the academic adjustment and the social and personal adjustment. Statistical significant differences were found between male and female students' personal, social and academic adjustment, in favor of the female students.

An overview on the previous literature revealed the scarcity of studies tackling academic adjustment and perceived self-efficacy together. The author attempted to fill such a gap and reveal the correlation between the two variables, and to develop practical and academic practices, the author hopes that this study may be a corner stone for other studies in light of the lack of studies combining the two variables of the academic adjustment and the perceived self-efficacy.

\subsection{Study Problem}

The topic of the perceived self-efficacy and academic adjustment has not received much interest from authors in the Arab environment, the topic is important in terms of its impact on the educational process and in attaining students interaction, academic achievement and positive behavior. Many behavior aspects may be interpreted in light of the perceived self-efficacy and academic adjustment. The scarcity of studies tackling academic adjustment and perceived self-efficacy together among undergraduates in the Arab environment and the importance of the topic on the educational process prompted the author to attempt exploring the correlation between the two variables. Accordingly, the current study tried to answer the following questions:

1) What is the level of the perceived self-efficacy among Qassim University students?

2) What is the level of the academic adjustment among Qassim University Students?

3) Is there a functional correlation between the level of the academic adjustment and the level of the perceived self-efficacy?

\subsection{Study Importance}

The study examines the impact of perceived self-efficacy on the academic adjustment among Qassim University students. This study may be considered a 
part of the theoretical and practical literature that highlights the impact of perceived self-efficacy on the academic adjustment, it may add new knowledge to the educational thought, and be the core for further studies in future. Lack of Arabic and local studies examining the impact of perceived self-efficacy on the academic adjustment urged the author to undertake the current study.

\subsection{Procedural Definitions}

For the purpose of the study the terms of perceived self-efficacy and academic adjustment are defined;

Perceived self-efficacy, is the learners' beliefs about their level of effectiveness and ability, the constituents included such as emotional, social, cognitive elements and determination and perseverance, it is measured by the scores achieved on the perceived self-efficacy test.

Academic Adjustment, is the mental process the learner performs to understand the study materials and to achieve success and harmonize between them and the university environment, it is measured by the scores achieved on the perceived self-efficacy test.

\subsection{Study Limitations}

Generalizing the results of the study may be inhibited through the following:

Validity and reliability of the tests: The sample was selected from Qassim University enrolled in the faculty of sciences and arts at Ar-Rass. Therefore, the results are valid to generalize only on the population of this study and similar populations.

\section{Methodology}

\subsection{Population}

The study population included all basic education students (No. 441), enrolled in Qassim University in the first semester of the academic year 2016/2017.

Sample. The sample was selected using a simple random technique, the participants were 150 student.

\subsection{Instruments}

The participants were instructed to complete the tests of the perceived self-efficacy and the academic adjustment. Next section of the study outlines the procedures of constructing and implementing the tests:

\subsubsection{Perceived Self-Efficacy Test}

The final version of the test included 35 items and was constructed by reviewing the tests of [10] [11] [13] studies in addition to surveying the students' opinions on the initial version of the test included 37 items. The participants completed the final version test, they answered each item by selecting the answer that describes their level of certainty on a 3-point Likert scale, (1) I agree, (2) I sometimes agree and (3) I disagree. 
Validity and Reliability of the Perceived Self-efficacy Test.

a) Surface Validity: competent professors majoring in psychology and education reviewed the initial version of the test in terms of the dimension representation, suitability to measure the perceived self-efficacy, and items structure, based on their comments two items are excluded and some items are modified, the total final number of the test items was 35, of the reviewers $80 \%$ agreed on items suitability. The overall answers of the test range between $0-70$. The first page on the test answer sheet explains the aim of it and instructions of answering. The test was implemented on a pilot sample of (20) students selected in random to inspect the clarity of instructions, items, and answering method, and to collect students views to insure the items ability to show the differences, the students comment were considered.

b) Construct Validity. The test was implemented on a pilot sample of (20) students to verify its validity. The correlation coefficients between the overall score and each item were computed, scores range between 0.40 - 0.76 degrees, as illustrated in Table 1.

All the correlation coefficient were acceptable and statistically significant, therefore, none of the items were excluded.

c) Test Stability. The pilot sample was tested and retested after an interval of two weeks and the results were computed by Pearson spearman between the estimates of the respondents in the two times. To insure the internal consistency based on Cronbach's Alpha it was computed from the responses of the pilot sample, the results obtained were considered appropriate for implementation, Table 2 illustrates these results.

Table 1. Correlation coefficient of the perceived self-efficacy test based on test dimensions and overall test.

\begin{tabular}{cccccc}
\hline N. & $\begin{array}{c}\text { Test correlation } \\
\text { coefficient }\end{array}$ & N. & $\begin{array}{c}\text { Test correlation } \\
\text { coefficient }\end{array}$ & N. & $\begin{array}{c}\text { Test correlation } \\
\text { coefficient }\end{array}$ \\
\hline 1 & $0.51^{* *}$ & 13 & $0.48^{* *}$ & 25 & $0.64^{* *}$ \\
2 & $0.65^{* *}$ & 14 & $0.64^{* *}$ & 26 & $0.54^{* *}$ \\
3 & $0.64^{* *}$ & 15 & $0.54^{* *}$ & 27 & $0.62^{* *}$ \\
4 & $0.61^{* *}$ & 16 & $0.43^{* *}$ & 28 & $0.62^{* *}$ \\
5 & $0.52^{* *}$ & 17 & $0.61^{* *}$ & 29 & $0.59^{* *}$ \\
6 & $0.54^{* *}$ & 18 & $0.40^{* *}$ & 30 & $0.58^{* *}$ \\
7 & $0.53^{* *}$ & 19 & $0.62^{* *}$ & 31 & $0.72^{* *}$ \\
8 & $0.58^{* *}$ & 20 & $0.48^{* *}$ & 32 & $0.44^{* *}$ \\
9 & $0.44^{* *}$ & 21 & $0.59^{* *}$ & 33 & $0.63^{* *}$ \\
10 & $0.71^{* *}$ & 22 & $0.66^{* *}$ & 34 & $0.76^{* *}$ \\
11 & $0.56^{* *}$ & 23 & $0.59^{* *}$ & 35 & $0.44^{* *}$ \\
12 & $0.66^{* *}$ & 24 & $0.43^{* *}$ & & \\
\hline
\end{tabular}

${ }^{*} \alpha$ functional at $(\alpha=0.05),{ }^{* *} \alpha$ functional at $(\alpha=0.01)$. 
Table 2. Cronbach internal consistency coefficient and retest reliability based on test variable and overall test of the perceived self-efficacy level.

\begin{tabular}{ccc}
\hline Dimension & Test Retest & Internal Consistency \\
\hline Emotional & 0.84 & 0.74 \\
Social & 0.88 & 0.71 \\
Determination and Perseverance & 0.86 & 0.70 \\
Cognitive & 0.83 & 0.77 \\
Overall Perceived Self-Efficacy & 0.89 & 0.84 \\
\hline
\end{tabular}

$\alpha^{*}$ functional at $(\alpha=0.05),{ }^{*} \alpha$ functional at $(\alpha=0.01)$.

d) Rating the Perceived Self-efficacy Test

The final version of the test included 35 items distributed on the emotional (10 items), the social ( 9 items), the determination and perseverance (8 items) and the cognitive ( 8 items) dimensions. The participants selected the answer from a 3-point Likert scale in front of each item that best suits their level of certainty. The degree of each item score ranges from $0-2$, and the overall degree ranges from $0-70$.

\subsubsection{Academic Adjustment}

The tests items were derived from a survey proposed to the study population, consulting previous literature and tests of academic adjustment. The test included 36 items distributed on three dimensions, the academic dimension (16 items), the tendency toward the university ( 9 items) and the teacher-learner relationship (11 items).

\section{Validity and Reliability of the Academic Adjustment Test.}

a) Surface Validity: five competent professors majoring in psychology reviewed the test items and provided some remarks in terms of the clarity of the items for the Arab population, their comments were considered in modifying some items. The total final number of items was (36) items. The participants completed the test items on a 3-point Likert scale; (1) represents agreement with the item, (2) represents sometimes agreement and (3) represents disagreement with the item. The overall answers of the test range between $0-72$. The first page on the test answer sheet explains the aim of it and instructions of answering. The test was implemented on the pilot sample of (20) students selected in random to inspect the clarity of instructions, items, and answering method, collecting students views and to insure the items ability to show the differences, the students comments were considered.

b) Construct Validity. The test was implemented on a pilot sample of (20) students to verify its validity. The correlation coefficients between the overall score and each item were computed, the results score range between $0.39-0.60$ degrees, and the coefficients results score for each item range between 0.38 - 0.69 degrees, as illustrated in Table 3 and Table 4.

All the correlation coefficient were acceptable and statistically significant, therefore, none of the items were excluded. 
Table 3. Correlation coefficient of the academic adjustment test based on test dimensions and overall test.

\begin{tabular}{ccccccccc}
\hline N. & $\begin{array}{c}\text { Correlation } \\
\text { coefficient with } \\
\text { the dimension }\end{array}$ & $\begin{array}{c}\text { Correlation } \\
\text { coefficient of } \\
\text { overall test }\end{array}$ & N. & $\begin{array}{c}\text { Correlation } \\
\text { coefficient with } \\
\text { the dimension }\end{array}$ & $\begin{array}{c}\text { Correlation } \\
\text { coefficient of } \\
\text { overall test }\end{array}$ & $\begin{array}{c}\text { N. } \\
\text { coefficient with } \\
\text { the dimension }\end{array}$ & $\begin{array}{c}\text { Correlation } \\
\text { coefficient of } \\
\text { overall test }\end{array}$ \\
\hline 1 & $0.49^{* *}$ & $0.41^{* *}$ & 15 & $0.62^{* *}$ & $0.50^{* *}$ & 29 & $0.38^{* *}$ & $0.52^{* *}$ \\
2 & $0.55^{* *}$ & $0.47^{* *}$ & 16 & $0.55^{* *}$ & $0.62^{* *}$ & 30 & $0.62^{* *}$ & $0.45^{* *}$ \\
3 & $0.41^{* *}$ & $0.45^{* *}$ & 17 & $0.64^{* *}$ & $0.42^{* *}$ & 31 & $0.61^{* *}$ & $0.42^{* *}$ \\
4 & $0.51^{* *}$ & $0.45^{* *}$ & 18 & $0.43^{* *}$ & $0.508^{* *}$ & 32 & $0.45^{* *}$ & $0.50^{* *}$ \\
5 & $0.51^{* *}$ & $0.55^{* *}$ & 19 & $0.40^{* *}$ & $0.49^{* *}$ & 33 & $0.41^{* *}$ & $0.49^{* *}$ \\
6 & $0.55^{* *}$ & $0.43^{* *}$ & 20 & $0.54^{* *}$ & $0.46^{* *}$ & 34 & $0.54^{* *}$ & $0.46^{* *}$ \\
7 & $0.69^{* *}$ & $0.57^{* *}$ & 21 & $0.60^{* *}$ & $0.39^{* *}$ & 35 & $0.60^{* *}$ & $0.39^{* *}$ \\
8 & $0.54^{* *}$ & $0.54^{* *}$ & 22 & $0.44^{* *}$ & $0.42^{* *}$ & 36 & $0.45^{* *}$ & $0.49^{* *}$ \\
9 & $0.51^{* *}$ & $0.44^{* *}$ & 23 & $0.60^{* *}$ & $0.51^{* *}$ & & & \\
10 & $0.58^{* *}$ & $0.45^{* *}$ & 24 & $0.60^{* *}$ & $0.42^{* *}$ & & & \\
11 & $0.38^{* *}$ & $0.41^{* *}$ & 25 & $0.53^{* *}$ & $0.47^{* *}$ & & & \\
12 & $0.60^{* *}$ & $0.49^{* *}$ & 26 & $0.55^{* *}$ & $0.49^{* *}$ & & & \\
13 & $0.57^{* *}$ & $0.41^{* *}$ & 27 & $0.52^{* *}$ & $0.49^{* *}$ & & & \\
14 & $0.53^{* *}$ & $0.43^{* *}$ & 28 & $0.53^{* *}$ & $0.51^{* *}$ & & & \\
\hline
\end{tabular}

$\alpha^{\star}$ functional at $(\alpha=0.05), \alpha^{* *}$ functional at $(\alpha=0.01)$.

Table 4. Consistency coefficient based on the test dimensions and overall test of the academic adjustment level.

\begin{tabular}{lcccc}
\hline \multicolumn{1}{c}{ Dimension } & Academic & $\begin{array}{c}\text { Tendency toward } \\
\text { the University }\end{array}$ & $\begin{array}{c}\text { The Teacher-Learner } \\
\text { Relationship }\end{array}$ & $\begin{array}{c}\text { Overall Academic } \\
\text { Adjustment }\end{array}$ \\
\hline Academic & 1 & & \\
Tendency toward the University & $0.619^{* *}$ & 1 & 1 \\
The Teacher-Learner Relationship & $0.564^{* *}$ & $0.799^{* *}$ & $0.856^{* *}$ & 1 \\
Overall Academic Adjustment & $0.828^{* *}$ & $0.926^{* *}$ & \\
\hline
\end{tabular}

$\alpha^{*}$ functional at $(\alpha=0.05), \alpha^{* *}$ functional at $(\alpha=0.01)$.

c) Test Stability. The same procedure conducted in the previous test was conducted here to compute the academic adjustment test stability. The pilot sample was tested and retested after an interval of two weeks and the results were computed by Pearson spearman between the estimates of the respondents in the two times. The internal consistency based on Cronbach's Alpha was computed from the responses of the pilot sample, the results obtained were considered appropriate for implementation, and Table 5 illustrates these results.

d) Rating the Academic Adjustment Test

The final version of the test included 36 items distributed on the three dimensions. The participants selected the answer from a 3-point Likert scale in front of each item that best suits their level of certainty. The overall degree range from 0 72 degrees that is the highest degree a respondent obtains is 72 and the least degree is 0 . 


\subsection{Procedures}

The author selected the population of the study from female students (No. 441) who were enrolled in the faculty of Science and Arts in Ar-Ras/Qassim University, for the academic year 2016/2017. The sample was selected through a simple random technique, one hundred and fifty students were selected to participate in the study, and the participants were subjected to the two tests of the perceived self-efficacy and the academic adjustment. The responses obtained were analyzed.

\subsection{Study Variables}

The perceived self-efficacy is the independent variable; it is measured by the scores achieved on the perceived self-efficacy test.

The academic adjustment is the dependent variable, it is measured by the scores achieved on the academic adjustment test.

Means, standard deviations and Pearson correlations were used in analyzing the data obtained.

\section{Results and Discussion}

The study aimed at recognizing the impact of perceived self-efficacy on the students' academic achievement by attempting to answer the proposed questions for that purpose.

To answer the first question of "What is the level of the perceived self-efficacy among Qassim University students?" means and standard deviations of the perceived self-efficacy level are calculated as illustrated in Table 6.

Table 5. Cronbach internal consistency coefficient and retest reliability based on the academic adjustment test items and overall test.

\begin{tabular}{lcc}
\hline \multicolumn{1}{c}{ Dimension } & Test Retest & Internal Consistency \\
\hline Academic & 0.83 & 00.8 \\
Tendency toward the University & 0.79 & 0.78 \\
The Teacher-Learner Relationship & 00.9 & 0.75 \\
Overall Academic Adjustment & 0.89 & 0.87 \\
\hline
\end{tabular}

$\alpha^{*}$ functional at $(\alpha=0.05),{ }^{*} \alpha$ functional at $(\alpha=0.01)$.

Table 6. Means and standard deviations of the perceived self-efficacy level in means descendant order.

\begin{tabular}{cccccc}
\hline Item N. & Item order & Dimension & Mean & Standard Deviation & Level \\
\hline 1 & 2 & Social & 1.61 & 0.202 & weak \\
2 & 3 & Determination and Perseverance & 1.50 & 0.321 & weak \\
3 & 4 & Cognitive & 1.41 & 0.240 & weak \\
4 & 1 & Emotional & 1.05 & 0.248 & weak \\
& & Overall Perceived Self-efficacy & 1.38 & 0.148 & weak \\
\hline
\end{tabular}


It is noticed in Table 6 that means scores range between 1.05 - 1.61 degrees, the social dimension score was first $(M=1.61)$, and the emotional dimension score was the last $(\mathrm{M}=1.05)$, the overall mean of the perceived self-efficacy score was 1.38. This weak result of the perceived self-efficacy may be attributed to the student's immaturity, that means they did not reach a stage where they depend on themselves, a stage that allow them to decide and increases the experiences supporting the direct and indirect knowledge and forms positive tendencies of the student ability, and therefore, increases the ability to cope in front of situations and take decisions. This result corresponds with the results of [10] and [13] studies, who found that females perceive their self-efficacy less than males, it also agrees with the study of [11], the authors found a weak level of the perceived self-efficacy among the learners, but when they were subjected to a program to enhance their perceived self-efficacy their performance improved. It also agrees with [12] study; the author connected the perceived self-efficacy with the test anxiety and found a negative functional correlation between the test anxiety and the perceived self-efficacy.

Means and standard deviations of the estimates of the respondents for each dimension are illustrated in Table 7.

It is inferred from Table 7 that the means scores range between $0.65-1.61$ degrees, item 10 "I can relax when I want to" scored the highest mean 1.72 and was ranked the first, this may be attributed to the high stressors and pressures toward which the student takes certain reduction procedures, if stress remained it turns to sickness, the students resolved to relax whenever they needed to. On the other hand, item 9 "I find it difficult to overcome hatred for some people" score was the least $(M=0.65)$ and was ranked the last, this result may be attributed to the student's emotional levels categorized as borderline personalities, these students do not communicate and interact with their classmates as a means of emotional relief. The means of the overall perceived self-efficacy score was 1.05 .

Table 7. Means and standard deviations of the emotional dimension in means descendant order.

\begin{tabular}{|c|c|c|c|c|c|}
\hline Item Order & Item No. & Item & Mean & Standard Deviation & Level \\
\hline 1 & 10 & I can relax when I want to. & 1.72 & 0.451 & Weak \\
\hline 2 & 7 & I lose the ability of laughter and jokes sharing. & 1.62 & 0.488 & Weak \\
\hline 3 & 3 & I lose control of my actions when I get angry. & 1.39 & 0.665 & Weak \\
\hline 4 & 6 & I am a calm and a balanced person & 1.10 & 0.714 & Weak \\
\hline 5 & 1 & I can control my emotions. & 1.05 & 0.608 & Weak \\
\hline 6 & 2 & I find it difficult to get rid of melancholy ideas. & 0.81 & 0.675 & Weak \\
\hline 7 & 5 & I can deal effectively with the life stressors facing me. & 0.81 & 0.741 & Weak \\
\hline 8 & 4 & I can overcome the feelings of worry. & 0.68 & 0.727 & Weak \\
\hline 9 & 8 & I find it difficult to stay calm for a long time. & 0.65 & 0.667 & Weak \\
\hline 10 & & Overall Emotional level & 1.05 & 0.248 & Weak \\
\hline
\end{tabular}




\section{The Social Dimension}

From Table 8 it is inferred that the means scores range from $1.37-1.94$ degrees, item number 11 "I find it difficult to speak with the others" means score was 1.91 and was ranked the first, while item number 19 "I believe no one deserve the advice" mean score was 1.37 degrees and was ranked the last, the overall means of the social dimension score was 1.61 degrees. The scores tell us that the low level of perceived self-efficacy affected the social efficacy negatively and impacted the prior perceptions of the students about the future.

The Determination and Perseverance Dimension

Table 9 presents the determination and perseverance dimension means, the scores range from 1.42 - 1.56 degrees, item 21 "I get frustrated when I fail" and 26 "I lose the ability to focus on long term tasks" score the highest means ( $\mathrm{M}=$ 1.56), item 25 "I have patience when I face difficult situations" score was the least with a means of 1.42 , and the overall score of the dimension was 1.50. This result may be attributed to the fact that the previous student life did not focus on the academic level, hence the student is surprised by the university life that

Table 8. Means and standard deviations of the social dimension in means descendant order.

\begin{tabular}{|c|c|c|c|c|c|}
\hline Item Order & Item No. & Item & Mean & Standard Deviation & Level \\
\hline 1 & 11 & I find it difficult to speak with the others. & 1.91 & 0.283 & Weak \\
\hline 2 & 16 & I look to my friends with admiration & 1.74 & 0.437 & Weak \\
\hline 3 & 14 & I find it difficult to deal with the others & 1.63 & 0.484 & Weak \\
\hline 4 & 12 & I can't make new friends & 1.62 & 0.486 & Weak \\
\hline 5 & 15 & I can't forgive the others if they insult me. & 1.58 & 0.496 & Weak \\
\hline 6 & 13 & My friends tell me about their problems. & 1.55 & 0.499 & Weak \\
\hline 7 & 17 & I can maintain intimate relations with my relatives. & 1.53 & 0.632 & Weak \\
\hline 8 & 18 & I can easily win the love of the others. & 1.52 & 0.632 & Weak \\
\hline 9 & 19 & I believe no one deserve the advice. & 1.37 & 0.484 & Weak \\
\hline \multicolumn{3}{|c|}{ Overall Social Dimension } & 1.61 & 0.202 & Weak \\
\hline
\end{tabular}

Table 9. Means and standard deviations of the determination and perseverance dimension in means descendant order.

\begin{tabular}{|c|c|c|c|c|c|}
\hline Item Order & Item No. & Item & Mean & Standard Deviation & Level \\
\hline 1 & 21 & I get frustrated when I fail & 1.56 & 0.525 & Weak \\
\hline 1 & 26 & I lose the ability to focus on long term tasks & 1.56 & 0.512 & Weak \\
\hline 3 & 20 & I can implement the plans I make to do something & 1.54 & 0.610 & Weak \\
\hline 4 & 24 & I retreat easily when I face problems & 1.50 & 0.565 & Weak \\
\hline 4 & 27 & I achieve my goals even if I fail several times & 1.50 & 0.565 & Weak \\
\hline 6 & 22 & I abandon tasks and work before I finish & 1.48 & 0.622 & Weak \\
\hline 7 & 23 & I work hard if I failed in a certain task & 1.45 & 0.563 & Weak \\
\hline 8 & 25 & I have patience when I face difficult situations & 1.42 & 0.546 & Weak \\
\hline \multicolumn{3}{|c|}{ Overall Determination and Perseverance Dimension } & 1.50 & 0.321 & Weak \\
\hline
\end{tabular}


demands her to be qualified and well prepared to the university life that prepares her to the academic life. The students' weak level of determination and perseverance creates a self-struggle and difficulty in learning the courses, the student either passes this period having difficulties and weakness or she stoops and get frustrated and despair.

\section{The Cognitive Dimension}

Table 10 illustrated the means of the cognitive dimension, the means scores range from 1.14 - 1.59 degrees, item 29 "I consider arts such as painting, music and theater a waste of time" means score was the highest $(\mathrm{M}=1.59)$, whereas item 32 "Text careful reading helps me to understand" score was the last $(\mathrm{M}=$ 1.14 ) and the overall cognitive dimension mean score was 1.41 , the academic adjustment is affected by stressful life events, the more the student is stressed the lower the academic adjustment level becomes, this explains the students opting for enjoyment of different types of arts to reduce the effect of the life stressful events.

To answer the second question of "What is the level of the academic adjustment among Qassim University Students?" the means and standard deviations of the academic adjustment level among the students is computed as Table 11 illustrates.

Means scores range in Table 11 from 1.05 - 1.28 degrees, academic adjustment level was low; several factors contribute to the low levels. The academic dimension means score was the highest $(M=1.28)$, this result is explained by the traditional role of the student as a receiving agent and a weak participant in the

Table 10. Means and standard deviations of the cognitive dimension in means descendant order.

\begin{tabular}{|c|c|c|c|c|c|}
\hline Item Order & Item No. & Item & Mean & Standard Deviation & Level \\
\hline 1 & 29 & I consider arts such as painting, music and theater a waste of time & 1.59 & 0.558 & Weak \\
\hline 3 & 34 & I find it hard to understand what I read & 1.48 & 0.528 & Weak \\
\hline 4 & 30 & I feel bored when I read books and scientific articles & 1.46 & 0.621 & Weak \\
\hline 5 & 33 & I find it difficult to remember things & 1.44 & 0.525 & Weak \\
\hline 6 & 35 & I learn to handle things quickly & 1.42 & 0.605 & Weak \\
\hline 7 & 28 & I possess a large amount of general information & 1.20 & 0.557 & Weak \\
\hline 8 & 32 & Text careful reading helps me to understand & 1.14 & 0.507 & Weak \\
\hline
\end{tabular}

Table 11. Means and standard deviations of the cognitive dimension in means descendant order.

\begin{tabular}{ccccccc}
\hline Item Order & Item No. & Dimension & Mean & Standard Deviation & Level \\
\hline 1 & 1 & Academic & 1.28 & 0.177 & Weak \\
2 & 2 & Tendency toward the University & 1.27 & 0.130 & Weak \\
3 & 3 & The Teacher-Learner Relationship & 1.05 & 0.206 & Weak & Weak \\
& & Overall Academic Adjustment & 1.21 & 0.106 &
\end{tabular}


educational process, the student role is limited to memorizing the course information and books, retrieving it in the memory and recalling it in the time of the test, which affects the academic adjustment. The teacher-learner relationship means score was the last $(\mathrm{M}=1.05)$, this result is caused by the teachers missing to encourage the students, care for them, provide them with the ideas, the educational materials and the strategies required in the academic field, and to recognize students expectations about themselves, in addition to increasing the awareness about the university system and environment, this may be attributed to several factors such as the teachers' academic concerns, the large number of the students in the classroom or lack of teachers' training. The current study recommends conducting studies to find the extent of teacher's adherence to roles in teaching the students and the obstacles hindering them. These results disagree with the results of [16], the authors found that students' adjustment is enviable for the first year students at the university to succeed in their college education, the sample academic level in the study was moderate, and the means score of the overall test was 1.21.

The Academic dimension

In Table 12 we can observe that the means scores range between $0.73-1.73$ degrees, item 11 "My attention is often distracted in the lecture" was first $(\mathrm{M}=$ 1.73), while item 2 "I always have test anxiety" was the last $(M=0.73)$, the overall

Table 12. Means and standard deviations of the academic dimension in means descendant order.

\begin{tabular}{|c|c|c|c|c|c|}
\hline Item Order & Item No. & Dimension & Mean & Standard Deviation & Level \\
\hline 1 & 5 & I trust my abilities in confronting new situations & 1.48 & 0.447 & Weak \\
\hline 2 & 14 & I try to achieve my goals even if it needed exhausting efforts & 1.56 & 0.498 & Weak \\
\hline 3 & 7 & I feel all my goals are realistic and achievable & 1.54 & 0.500 & Weak \\
\hline 4 & 9 & I feel my mental abilities are less than my peers & 1.48 & 0.621 & Weak \\
\hline 5 & 10 & I feel bored and distressed while reading & 1.48 & 0.621 & Weak \\
\hline 6 & 11 & My attention is often distracted in the lecture & 1.73 & 0.501 & Weak \\
\hline 7 & 16 & I participate in the discussions and dialogues in the lecture & 1.29 & 0.681 & Weak \\
\hline 8 & 6 & I have a strong desire to study & 1.24 & 0.672 & Weak \\
\hline 9 & 3 & I believe education is not beneficial compared to occupations & 1.21 & 0.691 & Weak \\
\hline 10 & 12 & I try to increase my knowledge from books beside the curriculum material & 1.21 & 0.559 & Weak \\
\hline 11 & 17 & I depend on my colleagues in completing my homework & 1.20 & 0.676 & Weak \\
\hline 12 & 1 & Studying agrees with my interests and tendencies & 1.19 & 0.739 & Weak \\
\hline 12 & 4 & I believe that all my subjects are difficult and I cannot understand them & 1.19 & 0.639 & Weak \\
\hline 14 & 13 & If I feel that I am not going to get caught in cheating, I cheat & 1.12 & 0.601 & Weak \\
\hline 15 & 8 & I study regularly & 1.11 & 0.604 & Weak \\
\hline 16 & 15 & $\begin{array}{l}\text { I don't think I can benefit from the courses I study at the college in the } \\
\text { practical life }\end{array}$ & 0.97 & 0.484 & Weak \\
\hline \multirow[t]{2}{*}{17} & 2 & I always have test anxiety & 0.73 & 0.785 & Weak \\
\hline & & overall academic dimension & 1.28 & 0.177 & Weak \\
\hline
\end{tabular}


means of the academic dimension score was 1.28 degrees. The two items may seem correlated; this result may be attributed to the fact that the test anxiety is natural and may be motivational to exhaust more effort and perseverance, but the anxiety should not exceed the normal limit, because if the student reached a high degree of test anxiety her attention would be distracted and may be venerable for certain physiological disorders. Anxiety and distraction may have several reasons such as postponing serious study to the night of the exam, rely on mere memorizing of the material, weakness in connecting ideas, lack of thinking about mental disorders and social problems, lack of self-capacity recognition, inability to summarize the study material, inability to identify clear basic ideas or lack of student's self-confidence.

The Tendency toward the University Dimension

It is inferred from Table 13 that the means scores range between $0.41-1.65$, item 27 "I feel the day at the university is too long" score was ranked first and a means of 1.65 , whereas item 24 "The university provides total freedom" score was ranked the last and a means of 0.41 , the overall tendency toward the university means score was 1.27 . the two items may seem correlated the first item ranked first and the second item ranked last, this result may be explained by the university rules providing transportation for the students, where the bus reaches the university at a certain time and leaves at a certain time, and the student is obliged to wait for the return even if she has one lecture only, the second item gives the students constrained freedom because students have to wear the uniform and the activities are limited in timing and type.

The Teacher-Learner Relationship

Table 14 showed that means scores range between 0.64 - 1.62, item 30 "I feel shy to communicate with my teacher" means was ranked the first and scored $(M=1.62)$, shyness is considered a form fear characterized by disorders when the student communicates with the teacher and it is provoked by the others, social

Table 13. Means and standard deviations of the tendency toward the university dimension in means descendant order.

\begin{tabular}{|c|c|c|c|c|c|}
\hline Item Order & Item No. & Item & Mean & Standard Deviation & Level \\
\hline 1 & 21 & I feel guilty if I am late in going to the university & 1.23 & 0.480 & Weak \\
\hline 2 & 20 & I prefer to be absent from the university whenever I can & 1.57 & 0.572 & Weak \\
\hline 3 & 23 & I can't wait for the start of the university & 1.54 & 0.500 & Weak \\
\hline 4 & 25 & I enjoy time in the university & 1.46 & 0.500 & Weak \\
\hline 5 & 26 & I feel ashamed if I violate the regulations of the university & 1.43 & 0.497 & Weak \\
\hline 6 & 22 & I feel that the university activities are a waste of time & 1.41 & 0.667 & Weak \\
\hline 7 & 27 & I feel the day at the university is too long & 1.65 & 0.657 & Weak \\
\hline 8 & 18 & I feel upset in the morning when the time to go to the university is near & 1.13 & 0.638 & Weak \\
\hline 9 & 19 & I get upset from adhering to the regulations of the university & 0.88 & 0.655 & Weak \\
\hline \multirow[t]{2}{*}{10} & 24 & The university provides total freedom & 0.41 & 0.493 & Weak \\
\hline & & Overall Tendency toward the University Dimension & 1.27 & 0.130 & Weak \\
\hline
\end{tabular}


Table 14. Means and standard deviations of the teacher-learner relationship dimension in means descendant order.

\begin{tabular}{|c|c|c|c|c|c|}
\hline Item Order & Item No. & Item & Mean & Standard Deviation & Level \\
\hline 1 & 30 & I feel shy to communicate with my teacher & 1.62 & 0.564 & weak \\
\hline 2 & 29 & The teacher refuses my point of view often & 1.59 & 0.519 & weak \\
\hline 3 & 37 & The teachers at the university deserve love and respect & 1.33 & 0.631 & weak \\
\hline 4 & 28 & I feel most of my teachers like me & 1.32 & 0.698 & weak \\
\hline 5 & 35 & The teachers care for the students feelings & 1.08 & 0.585 & weak \\
\hline 6 & 33 & I am afraid to answer the teachers' questions even if I knew the correct answer & 0.96 & 0.834 & weak \\
\hline 7 & 38 & I do not find answers from the teachers for my inquiries about the material & 0.88 & 0.590 & weak \\
\hline 8 & 32 & $\begin{array}{l}\text { I hesitate too much in asking the teachers about the material that } \\
\text { I do not understand }\end{array}$ & 0.75 & 0.593 & weak \\
\hline 9 & 31 & I feel that the teachers are unfair & 0.67 & 0.575 & weak \\
\hline 10 & 36 & I feel relieved if one teacher is absent from the lecture & 0.66 & 0.664 & weak \\
\hline \multirow[t]{2}{*}{11} & 34 & $\begin{array}{l}\text { I often find myself assailed by the desire to leave the class in the } \\
\text { middle of the lecture }\end{array}$ & 0.64 & 0.605 & weak \\
\hline & & Overall Teacher-Learner Relationship Dimension & 1.05 & 0.206 & weak \\
\hline
\end{tabular}

shyness prevails among adolescence and in Arab communities among females as a product of family socialization styles, for that reason the students feel shy to communicate with their teachers. Whereas item 34 "I often find myself assailed by desire to leave the class in the middle of the lecture" means score $(\mathrm{M}=0.65)$ the lowest and was ranked the last, this result is attributed to the fact of imposing a certain major on the student to study even if it is not her wish, imposing certain majors on students have several factors such as poor achievement in the prior year, the psychological and social changes, the misunderstanding of the university life meaning as being a period of absolute freedom, the student is free to attend or not, to participate or not, this is added to the weak counseling about the concepts of academic adjustment and achievement. The overall means score of the dimension 1.05 .

To answer the third question of "Is there a functional correlation between the level of the academic adjustment and the level of the perceived self-efficacy" Pearson correlations coefficients between the academic adjustment and the perceived self-efficacy are computed. Table 15 illustrates that.

From table it is inferred that there is a significant correlation between the emotional and the social dimension with the academic adjustment and all its dimensions. This result is attributed to the environment, education and emotional and social relationships more than the social and emotional properties, most of the studies argue this issue, and the results disagree with what [14] said; he found a relationship between academic adjustment and the psychosocial development. It also disagrees with the study of [5]; he found a correlation between the academic adjustment and the social and personal adjustment.

A positive statistically significant correlation between the determination and perseverance, the cognitive dimension and overall self-efficacy and the academic dimension and between academic adjustment as a whole was found. 
Table 15. Pearson coefficient correlation between the level of perceived self-efficacy and academic adjustment.

\begin{tabular}{|c|c|c|c|c|c|}
\hline Dimension & & Academic & $\begin{array}{l}\text { Tendency toward } \\
\text { the University }\end{array}$ & $\begin{array}{c}\text { The Teacher-Learner } \\
\text { Relationship }\end{array}$ & $\begin{array}{l}\text { Academic } \\
\text { Adjustment }\end{array}$ \\
\hline \multirow{3}{*}{ Emotional } & Pearson coefficient correlation $(r)$ & 0.091 & -0.032 & -0.004 & 0.056 \\
\hline & Statistical significance & 0.268 & 0.696 & 0.962 & 0.500 \\
\hline & No. & 149 & 149 & 149 & 149 \\
\hline \multirow{3}{*}{ Social } & Pearson coefficient correlation ( $\mathrm{r}$ ) & 0.101 & -0.145 & -0.085 & -0.020 \\
\hline & Statistical significance & 0.221 & 0.077 & 0.302 & 0.806 \\
\hline & No. & 149 & 149 & 149 & 149 \\
\hline \multirow{3}{*}{$\begin{array}{l}\text { Determination } \\
\text { and } \\
\text { Perseverance }\end{array}$} & Pearson coefficient correlation ( $\mathrm{r}$ ) & $0.437^{* *}$ & 0.138 & -0.063 & $0.337^{* *}$ \\
\hline & Statistical significance & 0.000 & 0.094 & 0.447 & 0.000 \\
\hline & No. & 149 & 149 & 149 & 149 \\
\hline \multirow{3}{*}{ Cognitive } & Pearson coefficient correlation $(r)$ & $0.316^{* *}$ & -0.019 & 0.030 & $0.247^{* *}$ \\
\hline & Statistical significance & 0.000 & 0.817 & 0.715 & 0.002 \\
\hline & No. & 149 & 149 & 149 & 149 \\
\hline \multirow{3}{*}{$\begin{array}{l}\text { Perceived } \\
\text { self-efficacy }\end{array}$} & Pearson coefficient correlation $(\mathrm{r})$ & $0.413^{* *}$ & -0.005 & -0.052 & $0.279^{* *}$ \\
\hline & Statistical significance & 0.000 & 0.95 & 0.531 & 0.001 \\
\hline & No. & 149 & 149 & 149 & 149 \\
\hline
\end{tabular}

$\alpha^{*}$ functional at $(\alpha=0.05), \alpha^{* *}$ functional at $(\alpha=0.01)$.

The result can be explained by the general academic and cognitive circumstances responsibility for the formation and enhancing of the self-efficacy, and increasing the academic adjustment among the students, these circumstances form students' positive tendencies, capabilities and potentials, and raise the ability of overall self-reliance and builds skills that may help the student.

\section{Implications}

In light of the results, the author suggests:

1) Creating counseling educational programs in order to recognize the students' problems, help them to solve it and provide psychological and educational support to increase their academic adjustment;

2) Enhancing the perceived self-efficacy among the students by implementing counseling programs created for that end;

3) Emphasizing the need to set workshops to educate teachers about the importance of the perceived self-efficacy;

4) Conducting more studies to fill the existing gap, and utilizing the results in developing the educational process.

\section{References}

[1] Hussein, M. (1987) The Self Concept and its Relation with Levels of Emotional Reassurance. Journal of the Social Sciences, 15, 103-128.

[2] Bong, M. (1997) Congruence of Measurement Specificity on Relation between Aca- 
demic Self-Efficacy Effort and Achievement Indexes. Eric Document Reproduction service, no.ed 411261 .

[3] Az-Zayat, F.M. (2001) Cognitive Psychology (Part 2): Introductions, Models and Theories. University Publishing, Egypt.

[4] Abd Al-Rahman, M. (1998) The Personality Theories. DārQibảlil-Tiba־ahwa-alNashr, al-Qahirah.

[5] Rashid, M. (2011) The Academic, Personal and Social Adjustment after Unifying the Streams in the Kingdom of Bahrain: A Field Study on High School Students in the Central Governorate. Damascus University Journal, 27, 701-740.

[6] Eysenck, H.J., Arnold, W. and Meili, R. (1979) Encyclopedia of Psychology. Seabury Press, New York.

[7] Ahmed, S. (2001) Mental Health of Children. Alexandria Book Center, Alexandria. Egypt.

[8] Alqraiti, A.M. (2003) Mental Health. 2nd Edition, Dar elfikrelarabi, Egypt.

[9] Sherbini, Z. and Belfaqih, N. (1998) The Students' Academic Adjustment Measure of High School in the Emirate of Fujairah. Anglo-Egyptian Library, Egypt.

[10] Hanover, B (2002) Investigation of the Role of the Gender in Developing Self-Efficacy, the Development Social Psychology of Gender. N.J. Lawrence-Erlbaum Associates.

[11] Akanbi, S.T. and Ogundokun, M.O. (2006) Effectiveness of Self-Efficacy Strategies as Method of Reducing Test Anxiety of Student Nurses in Ogbomosho North Local Government Area, Oyo State, Nigeria. African Journal of Cross-Cultural Psychology and Sport Facilitation, 18, 18-26.

[12] Nasasrah, F.S. (2009) Perceived Self-Efficacy and Its Relation with Examination Anxiety in Light of Demographical Variables among High School Students in Be'er Sheva. Unpublished Master's Thesis, Yarmouk University, Jordan.

[13] Alwan, S. (2013) Perceived Self-Efficacy among Baghdad University Students. Educational and Psychological Research Journal, 33, 224-242.

[14] Az-Zahrani, N. (2005) The Sociopsychological Development Based on Ericson's Theory and Its Relationship with the Academic Achievement among High School Students in Taif. Unpublished Master's Thesis, Umm Al Qura University, Saudi Arabia.

[15] Mohanraj, R. and Lath (2005) Perceived Family Environment in Relation to Adjustment and Academic Achievement. Journal of the Indian Academy of Applied Psychology, 31, 18-23.

[16] Abdullah, M.C., Elias, H., Mahyuddin, R. and Uli, J. (2009) Adjustment among First Year Students in a Malaysian University. European Journal of Social Science, 8, 496505. 
Submit or recommend next manuscript to SCIRP and we will provide best service for you:

Accepting pre-submission inquiries through Email, Facebook, LinkedIn, Twitter, etc. A wide selection of journals (inclusive of 9 subjects, more than 200 journals)

Providing 24-hour high-quality service

User-friendly online submission system

Fair and swift peer-review system

Efficient typesetting and proofreading procedure

Display of the result of downloads and visits, as well as the number of cited articles Maximum dissemination of your research work

Submit your manuscript at: http://papersubmission.scirp.org/

Or contact jss@scirp.org 